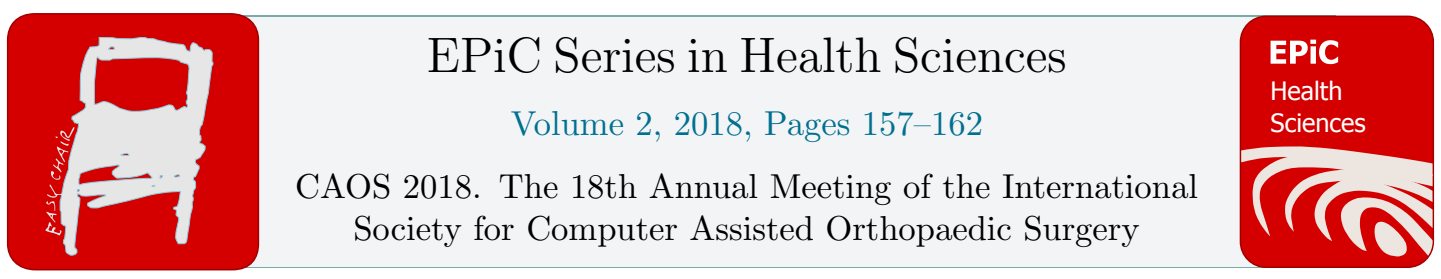

\title{
Does robotic-arm assisted total hip arthroplasty benefit short-term clinical outcomes? A pair match-controlled study
}

\author{
Itay Perets ${ }^{1,2}$, John Walsh ${ }^{1}$, Brian Mu ${ }^{1}$, Yosif Mansor ${ }^{1,3}$, Leslie Yuen ${ }^{1}$ and Benjamin Domb ${ }^{1,4}$ \\ ${ }^{1}$ American Hip Institute, Westmont, Illinois, USA \\ ${ }^{2}$ Hadassah Hebrew University Hospital, Jerusalem, Israel \\ ${ }^{3}$ Chaim Sheba Medical Center at Tel Hashomer, Ramat Gan, Isreal \\ ${ }^{4}$ Hinsdale Orthopaedics, Westmont, Illinois, USA \\ drdomb@americanhipinstitute.org
}

\section{Introduction}

As in many fields, robotic technology has offered the opportunity to improve accuracy and precision in THA implantation. Robotic-arm assisted THA has been shown to result in significantly more accurate positioning of implants in vivo ${ }^{1}$. Other studies have suggested that robotic assistance reduces leg length discrepancy and allows for smaller, bone-preserving implants in THA ${ }^{2}$.

What has yet to be determined, however, is how robotic-arm assisted THA translates into clinical outcomes. The additional financial costs and learning curve associated with surgical robotic systems demand a clear benefit to the patient to justify their use.

The purpose of this study was to report clinical outcomes at minimum two-year follow-up for patients who underwent robotic-arm assisted THA compared to a pair-matched control group of patients who underwent manual THA.

\section{Methods}

Prospective data collection extended through the study period from July 2011 to January 2015. Patients were included in the study if they underwent primary THA with robotic-arm assistance to treat idiopathic osteoarthritis, performed by the senior author (BGD). At a minimum of two years after surgery, outcomes data were collected through questionnaires distributed during office visits, by encrypted email, or over telephone. Complete follow-up included collection of the Harris Hip Score (HHS) and Forgotten Joint Score (FJS-12) patient-reported outcome (PRO) measures, a 0-10 visual analog scale (VAS) for pain, and patient satisfaction on a 0-10 scale ${ }^{3,4}$. Additionally, any postoperative complications or subsequent ipsilateral hip surgeries were noted. 
Each patient who underwent robotic-arm assisted THA was matched to a patient who underwent primary THA by the senior author (BGD) using freehand technique without robotic assistance. Patients were matched 1:1 for age, sex, BMI, and surgical approach (anterior vs. posterior). This study was approved by the institutional review board.

\section{Results}

There were 353 eligible robotic-arm assisted THAs performed during the study period, 295 (83.6\%) of which had complete minimum two-year follow-up. Eighty-five robotic-arm assisted THAs were successfully pair-matched to controls. As shown in Table 1, there were no statistically significant differences in demographic factors between study groups, indicating adequate control by the pairmatching process.

\begin{tabular}{|c|c|c|c|}
\hline & МАKO & Control & $p$-value \\
\hline Hips & 85 & 85 & \\
\hline Patients & 80 & 78 & \\
\hline Age (years) & $57.0 \pm 9.1(37.6-79.1)$ & $56.6 \pm 9.6(34.2-81.0)$ & 0.798 \\
\hline Sex & & & $>0.999$ \\
\hline Female & $48(56.5 \%)$ & $48(56.5 \%)$ & \\
\hline Male & $37(43.5 \%)$ & $37(43.5 \%)$ & \\
\hline BMI $\left(\mathrm{kg} / \mathrm{m}^{2}\right)$ & $28.2 \pm 3.7(20.0-36.5)$ & $28.1 \pm 4.4(18.9-40.4)$ & 0.777 \\
\hline Laterality & & & 0.539 \\
\hline $\begin{array}{r}\text { Left } \\
\end{array}$ & $42(49.4 \%)$ & $37(43.5 \%)$ & \\
\hline Right & $43(50.6 \%)$ & $48(56.5 \%)$ & \\
\hline Approach & & & $>0.999$ \\
\hline Anterior & $37(43.5 \%)$ & $37(43.5 \%)$ & \\
\hline Posterior & $48(56.5 \%)$ & $48(56.5 \%)$ & \\
\hline
\end{tabular}

Table 1: Demographics

The patients who underwent THA with robotic assistance had significantly higher scores than the control group both for HHS $(p<0.001)$ and FJS-12 $(p=0.003)$. They trended towards lower VAS, 
although these differences were not statistically significant $(p=0.120)$. There was no difference in patient satisfaction between the groups. $(\mathrm{p}=0.591)$. Outcomes data are illustrated in Figure 1.

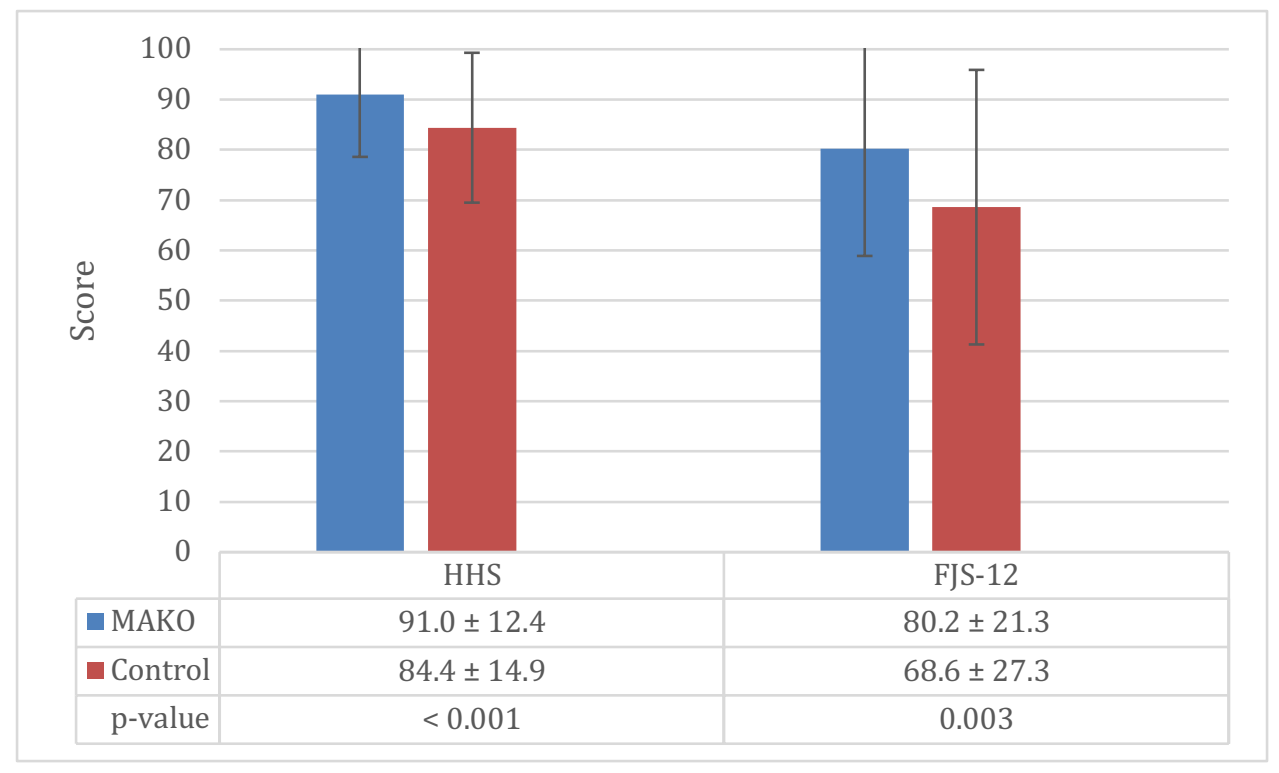

Figure 1: Patient Reported Outcomes

There was no significant difference in the rate of complications or subsequent revisions between groups.

\section{Discussion}

Correct positioning of implants during THA is essential for achieving good outcomes for a patient. Previous studies have suggested difficulty in consistent implant placement using the freehand technique. Callanan et al. reviewed radiographs of 1823 THAs and hip resurfacings in the Massachusetts General Hospital joint registry and found that only $50.3 \%$ of acetabular cups were within the safe zone for both abduction and version ${ }^{5}$. In a study of 200 THAs performed by three orthopedic surgeons and nine residents, Bosker et al. found that $70.5 \%$ had accurate placement ${ }^{6}$. Component malposition has been shown to be associated with serious negative consequences, such as increased polyethylene wear, osteolysis, and dislocations ${ }^{7-9}$.

Surgical robotic systems developed in recent years to assist implantation in THA have offered the ability to improve accuracy and precision. Nawabi et al. studied 12 cadaveric cup implantations and found that the robotic system was significantly more accurate to ideal cup orientation, concluding that robotic assistance has the potential to eliminate human error in THA ${ }^{10}$. Domb et al. compared the postoperative radiographs of 50 robotic-arm assisted THAs to a pair-matched control group of conventional posterior THAs performed by the same surgeon ${ }^{1}$. They found that cup components 
implanted with robot assistance were significantly more likely to be positioned within the safe zone as defined by both Lewinnek et al. and Callanan et al., with 100\% accuracy for the former. A review of 1980 THAs performed by six surgeons at the same institution found that techniques using computer navigation or robotic-arm assistance were significantly more accurate to the safe zones ${ }^{11}$. SuarezAhedo et al. also found that robotic-arm assistance allowed for relatively smaller component sizes, suggesting greater preservation of native bone stock ${ }^{12}$. Illgen et al. reported on 100 robotic-arm assisted THAs in comparison to manual THAs performed both early and late in clinical practice ${ }^{13}$. This study found that robotic-arm assistance led to both a $71 \%$ increase in accuracy of cup component placement and a significantly lower rate of dislocations ${ }^{14}$.

The current study demonstrates statistically higher scores at minimum two-year follow-up for robotic-arm assisted THAs using two separate PRO measures. Although other factors, such as the financial cost, increased operative times, or complications that may accompany the initial learning curve must remain considerations, the results of this study suggest that the use of robotic-arm assistance in THA may lead to improved outcomes for patients and therefore warrants continued pursuit. Longerterm studies will elucidate further unresolved issues in the field of robotic-arm assisted THA. In particular, as more data become available, rates of relatively uncommon events such as revision THA and dislocation will be more readily studied.

\section{Conclusion}

Performing THA with robotic-arm assistance may be of benefit to short-term patient outcomes compared to manual THA. There were no differences found regarding the rate of complications or subsequent revisions between groups, suggesting the procedure is safe compare to manual THA. 


\section{References}

1. Domb BG, El Bitar YF, Sadik AY, Stake CE, Botser IB. Comparison of robotic-assisted and conventional acetabular cup placement in THA: a matched-pair controlled study. Clin Orthop. 2014;472(1):329-336. doi:10.1007/s11999-013-3253-7

2. Chahal J, Thiel GSV, Mather RC, Lee S, Salata MJ, Nho SJ. The Minimal Clinical Important Difference (MCID) And Patient Acceptable Symptomatic State (PASS) For The Modified Harris Hip Score And Hip Outcome Score Among Patients Undergoing Surgical Treatment For Femoroacetabular Impingement. Orthop J Sports Med. 2014;2(2 Suppl). doi: $10.1177 / 2325967114$ S00105

3. Harris WH. Traumatic arthritis of the hip after dislocation and acetabular fractures: treatment by mold arthroplasty. An end-result study using a new method of result evaluation. J Bone Joint Surg Am. 1969;51(4):737-755.

4. Behrend H, Giesinger K, Giesinger JM, Kuster MS. The "forgotten joint" as the ultimate goal in joint arthroplasty: validation of a new patient-reported outcome measure. J Arthroplasty. 2012;27(3):430-436.e1. doi:10.1016/j.arth.2011.06.035

5. Callanan MC, Jarrett B, Bragdon CR, et al. The John Charnley Award: risk factors for cup malpositioning: quality improvement through a joint registry at a tertiary hospital. Clin Orthop. 2011;469(2):319-329. doi:10.1007/s11999-010-1487-1

6. Bosker BH, Verheyen CCPM, Horstmann WG, Tulp NJA. Poor accuracy of freehand cup positioning during total hip arthroplasty. Arch Orthop Trauma Surg. 2007;127(5):375-379. doi:10.1007/s00402-007-0294-y

7. Kennedy JG, Rogers WB, Soffe KE, Sullivan RJ, Griffen DG, Sheehan LJ. Effect of acetabular component orientation on recurrent dislocation, pelvic osteolysis, polyethylene wear, and component migration. J Arthroplasty. 1998;13(5):530-534.

8. Leslie IJ, Williams S, Isaac G, Ingham E, Fisher J. High cup angle and microseparation increase the wear of hip surface replacements. Clin Orthop. 2009;467(9):2259-2265. doi:10.1007/s11999009-0830-x

9. Gallo J, Havranek V, Zapletalova J. Risk factors for accelerated polyethylene wear and osteolysis in ABG I total hip arthroplasty. Int Orthop. 2010;34(1):19-26. doi:10.1007/s00264-009-0731-3 
10. Nawabi DH, Conditt MA, Ranawat AS, et al. Haptically guided robotic technology in total hip arthroplasty: a cadaveric investigation. Proc Inst Mech Eng [H]. 2013;227(3):302-309. doi: $10.1177 / 0954411912468540$

11. Domb BG, Redmond JM, Louis SS, et al. Accuracy of Component Positioning in 1980 Total Hip Arthroplasties: A Comparative Analysis by Surgical Technique and Mode of Guidance. J Arthroplasty. 2015;30(12):2208-2218. doi:10.1016/j.arth.2015.06.059

12. Suarez-Ahedo C, Gui C, Martin TJ, Chandrasekaran S, Lodhia P, Domb BG. Robotic-arm assisted total hip arthroplasty results in smaller acetabular cup size in relation to the femoral head size: a matched-pair controlled study. Hip Int J Clin Exp Res Hip Pathol Ther. 2017;27(2):147-152. doi:10.5301/hipint.5000418

13. Illgen RL, Bukowski BR, Abiola R, et al. Robotic-Assisted Total Hip Arthroplasty: Outcomes at Minimum Two-Year Follow-Up. Surg Technol Int. 2017;30:365-372.

14. Redmond, JM, Gupta, A, Hammarstedt, JE, Petrakos,AE, Finch, NA, Domb, BG. The learning curve associated with robotic-assisted total hip arthroplasty. J Arthroplasty. 2015 Jan;30(1):50-4. doi:10.1016/j.arth.2014.08.003. Epub 2014 Aug 8. 